\title{
Evaluating the Effect of 12 Weeks Football Training on the Posture of Young Male Basketball Players
}

\author{
Defne Öcal Kaplan \\ Correspondence: Defne Öcal Kaplan, Kastamonu University School of Physical Education and Sports, Kastamonu, \\ Turkey.
}

Received: July 9, $2018 \quad$ Accepted: July 31, $2018 \quad$ Online Published: August 3, 2018

doi:10.11114/jets.v6i10.3423

URL: https://doi.org/10.11114/jets.v6i10.3423

\begin{abstract}
Posture is the most healthy and correct placement of each region in the body when compared to the whole body. The predominantly use of one side of the body disrupts the posture. A bad posture changes the center of gravity of the body and causes chronic skeletal and muscle soreness. It is aimed to determine whether there is a rehabilitative effect of football training that does not require the use of dominant arms on posture asymmetries which may occur in the basketball which requires the use of dominant arm and leg in the study.

15 male basketball players who played basketball for an average of 8 years with a mean age of $21.7 \pm 1.5$ years participated as volunteers. Postures of the subjects were measured with PostureScreen Mobile $®$ before and after 12 week football trainings with lateral and anteriorly taken photographs. SPSS 22 was used program for statistical analysis. While analyzing of data Wilcoxon Test method was used and it is determined as significance level was $\mathrm{p}<0.05$.

After 12 weeks of football training, statistically significant differences were found in measurements taken from the anterior and lateral positions on the head, shoulder, ribcage, hip, and knee measured tilts and shifts. Estimated average head weight decreased depending on the posture of the cervical vertebrae and a significant difference was detected. Postures of subjects came close to the correct posture.

Basketball is an acycle sport branch that requires the use of muscles on the dominant side. It creates an asymmetric position on the athlete due to this feature; causes shifting and tilts. In order to eliminate postural disorders that occur, the effectiveness of football training that does not require to use of the dominant side of the body has been demonstrated.
\end{abstract}

Keywords: basketball, posture, posturescreen mobile®, football training

\section{Introduction}

Posture is defined as a proper alignment of body parts and is an important health indicator and a motor habit accompanying daily activities (Kendall, McCreary, \& Provance, 2005). Postural control is a necessary skill for all physical activities. In order to maintain postural control, the flexor and extensor muscles play an important role by working in a synergistic reverse manner (Trew \& Everett 1997). Balance is one's ability to hold their center of gravity within the supporting surface. Posture (static balance) is the continuation of the individual static position. Postural performance (dynamic balance) is the active control of the posture and position of the body in order to be able to move adequately and effectively without falling while at rest or in motion, in different environments and situations (Shumway-Cook, \& Horak, 1986).

Posture and gait are controlled by genetic and acquired motor programs. Sedentary adults have an automatic, fully symmetrical and repeatable motion mechanism. Characteristic features of locomotor movements seen in adults are not acquired until the age of 7-9 (Shmidt \& Wrisberg, 2008). Branch-specific sports education is repeatable and stereotyped, and it includes the training of body to learn the automatized movements. Motor movements show differences in sports branches. Branches such as handball, tennis or basketball require postural balance and rapid movements. The aim of postural balance is to ensure that the movement is done in the best way possible and eliminate the risk of falling. The use of racket and ball requires the selective use of a part of the upper or lower extremity. Intensive training in a single-sided sports branch causes muscle asymmetry (Anderson, \& Sidaway, 1994). A good mechanical posture is not always necessary for good balance. High-level skills and muscle properties allow excellent balance in branches such as basketball even in adverse conditions (Knudson, 2007). 
Postural abnormalities are common and are directly proportional to the daily activities of people. A weak posture, which is usually attributed to the lack of physical activity, is particularly evident in people who spend a long time sitting in front of the computer or table, as in many jobs in developed countries (Poca, Sahuquillo, Topczewski, Lastra, Font, \& Corral, 2006). In addition to inactive life, many branches that require the unilateral use of the body are found to cause postural disorders of athletes, especially in the sagittal plane. Basketball is an acyclic sports branch, and its training requires the use of dominant side and high level of endurance. Especially during adolescence and before then, due to the immaturity of musculoskeletal structures, it can affect the growth and can lead to the development of various postural disorders (Guedes \& João, 2014). Postural abnormality is the main cause of many musculoskeletal problems including stress, pain and various diseases. Identification of postural abnormalities and their causes are important to understand the sources of pain and limited movement, and to develop strategies such as corrective exercises (Fernández-de-Las-Peñas, Cuadrado, \& Pareja, 2006; Sung, Yoon, \& Park, 2015). Rehabilitative exercises including cyclic sports that do not only use the dominant side (football, swimming, cycling), should be preferred in order to correct postural abnormalities caused by the use of one side of the body.

Nowadays, new methods that can be used by anyone at any place and can provide reliable and valid results in the correct conditions have been developed in addition to the technologies that are analysed for laboratories and can be used by experts only such as X-Ray imaging devices, 3D movement analysers (Ferreira, Duarte, Maldonado, Burke, \& Marques, 2010). PostureScreen Mobile ${ }^{\circledR}$ (PostureCo Inc., Trinity, FL, USA) is a new, easy-to-access digital mobile application that enables to detect the deviations from ideal standing.

In the light of this information, it is aimed to investigate whether there is a rehabilitative effect of football training, which does not require dominant upper and lower limb use, on postural abnormalities that may occur due to playing basketball which necessitates the use of dominant arms and legs.

\section{Method}

\subsection{Study Group}

15 healthy male basketball players who played basketball for an average of 8 years were voluntarily participated in the study with a mean age of $21.7 \pm 1.5$ years, a mean height of $181.53 \pm 4.96 \mathrm{~cm}$ and a mean body weight of $76.20 \pm 8.55$ $\mathrm{kg}$.

\subsection{Demographic Data}

Basketball players' answers to individual questions such as date of birth, sports background, metabolic illnesses, whether they are on a diet or not, were taken and homogeneity was achieved within the study group.

\subsection{Measurements}

The height of subjects was measured using a Harpenden brand anthropometer with a sensitivity of $0.01 \mathrm{~cm}$ and body weight was measured using a digital scale sensitive to $100 \mathrm{gr}$ (Lohman, Roche, \& Martorell, 1988).

Pre-test, post-test posture analyses of subjects were performed using the PostureScreen Mobile program, with lateral and anterior views according to the procedure, and analysed based on reference points.

\subsection{Exercise Program}

Athletes who played basketball for an average of 8 years were given basic football training for 2 hours 3 days a week and did not play basketball during this period.

\subsection{Statistical Analysis}

The arithmetic mean and standard deviations of test results of the 15 study groups in the study were calculated. The normal distribution of the measurements of the study group was tested by the Shapiro-Wilk test. The data were analysed with the Wilcoxon Test using the SPSS 22 program, and the level of significance was accepted as $p<0.05$.

\section{Results}

15 athletes with a mean age of $21.73 \pm 1.49$ years who were playing basketball for an average of 8 years had a mean height of $181.53 \pm 4.96 \mathrm{~cm}$ and a body weight of $76.20 \pm 8.55 \mathrm{~kg}$.

The mean and standard deviation values of the data obtained before and after football training and the Paired Samples t-test results are shown in table 1. Significant differences were found after 12 weeks of football training in all of the parameters used to assess posture. 
Table 1. Comparison of the mean and standard deviation values of posture measurements and results of pre-test post-test in basketball players

\begin{tabular}{|c|c|c|c|c|}
\hline \multirow{2}{*}{ Variable } & \multicolumn{2}{|c|}{ Mean \pm sd } & \multirow{2}{*}{$\mathbf{Z}$} & \multirow{2}{*}{$\begin{array}{c}\text { Sig. } \\
\text { (2-tailed) }\end{array}$} \\
\hline & Pre-test & Post-test & & \\
\hline Height & $181.53 \pm 4.96$ & $181.80 \pm 4.89$ & -1.441 & .157 \\
\hline Weight & $76.20 \pm 8.55$ & $75.15 \pm 7.80$ & -1.918 & .055 \\
\hline Head shift & $0.52 \pm 0.31$ & $0.44 \pm 0.23$ & -2.201 & $.028 *$ \\
\hline Head tilt & $1.84 \pm 1.27$ & $1.05 \pm 0.88$ & -2.936 & $.003 *$ \\
\hline Shoulder shift & $0.55 \pm 0.21$ & $0.39 \pm 0.17$ & -3.409 & $.001 *$ \\
\hline Shoulder tilt & $3.71 \pm 0.68$ & $2.71 \pm 0.64$ & -3.408 & $.001 *$ \\
\hline Rib cage shift & $0.39 \pm 0.18$ & $0.16 \pm 0.09$ & -3.411 & $.001 *$ \\
\hline Hip shift & $0.83 \pm 0.57$ & $0.65 \pm 0.55$ & -3.408 & $.001 *$ \\
\hline Hip tilt & $2.91 \pm 0.72$ & $1.89 \pm 0.61$ & -3.408 & $.001 *$ \\
\hline Head shift lateral & $1.61 \pm 0.96$ & $1.35 \pm 0.71$ & -2.366 & $.018 *$ \\
\hline Shoulder shift lateral & $1.44 \pm 0.82$ & $0.96 \pm 0.66$ & -3.408 & $.001 *$ \\
\hline Hip shift lateral & $0.88 \pm 0.51$ & $0.50 \pm 0.33$ & -3.408 & $.001 *$ \\
\hline Knee shift lateral & $3.06 \pm 1.15$ & $2.23 \pm 0.91$ & -3.409 & $.000 *$ \\
\hline Head weight & $5.71 \pm 1.04$ & $5.67 \pm 1.04$ & -1.633 & .102 \\
\hline Effective head weight & $15.79 \pm 5.93$ & $13.27 \pm 4.92$ & -3.409 & $.001 *$ \\
\hline
\end{tabular}

Fourteen parameters were evaluated in postural analysis and significant differences were found in upper extremity and shoulder measurements as expected. Significant differences were found in the lower side measurements after training, and a significant difference in estimated head weight was obtained due to postural improvements.

\section{Discussion}

The data from the study shows that 12-week general football training has a significant impact on the posture of basketball players. Many studies that are done before have similar results to this study's data.

Nowadays many posture studies are performed using the posture screening mobile program as an alternative to classical methods which are expensive, time-consuming, and require expertise and a special field (Pano, Çina, Murataj, Krist, \& Rusi, 2015; Edward \& Alcantara, 2014). An easy-to-use software that does not require expertise to measure body angles and lengths is developed (Ferreira \& et al., 2010). It is stated that posture screening mobile program can be used safely in posture analysis and head position can be evaluated with this technology (Boland Neufeld, Ruddell, Dolezal, \& Cooper, 2016). Stolinski et al. (2017) have demonstrated the reliability of photographic measurements by comparing the conventional posture measurement methods used with measurements done on photographs. The study to demonstrate the reliability and validity of mobile applications in postural analysis has proven their usefulness in clinical and field surveys (Szucs \& Brown, 2018). Anterior-posterior curvatures were analyzed by computer-assisted photogrammetry before and after 6-month swimming and in-water exercises of 94 scoliotic children aged 8-13 years, and functional assessment of musculoskeletal system was performed. A significant increase in height and spinal length of subjects, and a statistically significant decrease in body curving angle, thoracic kyphosis, lumbar lordosis and shoulder motility were found (Barczyk-Pawelec, Bańkosz, \& Derlich, 2012).

The level of physical activity is related to postural development due to its effects on physical development. Sports exercises are often performed under asymmetric or heavy loads and are intended to improve specific skills. It is especially applied to very young individuals and can cause postural disorders (Sławińska, Rożek, \& Ignasiak 2006).

Basketball players and control group were compared in order to determine postural in adolescent basketballs, and it was determined that the basketball group had a lateral spinal curve and had head position on right sagittal plane, pelvic tilt, thoracic kyphosis. Basketball trainings affect the musculoskeletal system of adolescents and reflect their postural adaptation processes (Guedes \& et al., 2014). Anterior-posterior vertebral curves of control group consisting of 57 women, 104 men and 63 women and 99 men aged 14-17 who played volleyball, basketball and handball were compared. It is found that male volleyball players have more thoracic kyphosis than basketball players and that there is a significant difference in the thoracic kyphosis and lumbar lordosis between athletes and control group (Grabara, 2014). 
Spinal deformities were observed in children aged 10-12 years old who were playing basketball and it was found that the prevalence of spinal deformity in males was significantly higher than that of females with $65.1 \%$ and that basketball training may cause spinal deformity (Puzovic, Rotim, Jurisic, Samardzic, Zivkovic, Savic, \& Rasulic, 2015).

Similarly, the postures of basketball players and sedentary people were compared and basketball was reported to lead to postural disorders (Kayacan, Çiftçioğlu, \& Soslu, 2014). Postures of 73 football players and 78 sedentary people were measured and compared by posturography method and it was found that the footballers had more symmetrical pelvis positions in the frontal plane and had a more straight lumbar lordosis (Grabara, 2012). Netake et al. (2010) aimed to reveal the postural effect of different sports branches and found a significant relationship between the branches and vertebral curvature. Shoulder asymmetries of the volleyball and handball players were compared with the control group and it was determined that the scapula on the dominant side of the athletes were more inclined forward and the use of the dominant upper limb as adaptation to the branch training was reported to be the cause (Riberio \& Pascoal, 2013). Similarly, both shoulder structures of professional baseball players were examined, and significant differences were observed in scapular and glenohumeral mobilities on the shooting side, and this was described as the physical adaptation to the sports branch (Downar \& Sauers, 2005). Similar to these research in a study done to reveal the correlation between the sports branch oriented exercises and the posture and asymmetric built of the table tennis players, table tennis players were found to have a more kyphotic body posture compared to sedentary people and they were found to have various asymmetries in the frontal and transverse plane. This is due to the fact that table tennis is characterized by the intense and unilateral use of body muscle during the activity. (Barczyk \& et al., 2012). In the study of the frequency of postural disorders in children who did and did not play sports, the incidence of back asymmetry in girls playing basketball was high and the incidence of hyperlordosis in boys playing football was low (Boldori, Da Soldà, \& Marelli, 1999). The effect of physical exercises on the posture of 20 students between the ages of 6 and 9 was examined, posture analysis was performed with PostureScreen Mobile at intervals of 6 months, and significant differences were found between the two measurements (Cosma, Ilinca, Rusu, Nanu, \& Burileanu, 2015). In a study investigating the effects of school habits on children's posture, postures of 38 students were measured for one year using digital image-based posture assessment software, and it was found that the positions of lumbar vertebrae on sagittal plane and knees on frontal plane significantly changed and scoliosis decreased (Nichele da Rosa, Noll, Sedrez, Furlanetto, \& Candotti, 2016).

The walking patterns of right-dominant swimmers, basketball players, and football players were compared, and no statistically significant difference was found between the gait variables on the right and the left side of the swimmers, but the swing time and on the right side of the basketball players were recorded longer than the left side. The step length, the late swing phase and the right propulsion double support period on the right side of football players were calculated to be higher than the left side. These results were associated with spontaneous postural changes due to jumping or throwing and resulted in the gait asymmetry to be attributed to asymmetric muscle development. The right propulsion double support duration, right cycle duration, and right late swing phase duration were respectively longer than those on the left side for the basketball players. (Leroy, Polin, Tourny-Chollet, \& Weber, 2000). While all these studies are parallel to the data of the study, Jandrić (2016) compared the postures of young sedentary people with handball players based on the idea that physical activity and sports can affect postural disorders in children and determined that handball players have less postural disorders. The specificity of movements performed during the training applied in a particular sport may influence the shape of anterior-posterior curvatures of the spine and thus the type of body posture (Lichota, Plandowska, \& Mil, 2011).

Two separate thera-band exercises were performed on 30 healthy subjects for 6 weeks to provide ankle rehabilitation using thera-band exercise protocols and to study the effects of resistance training on postural control, and as a result, it was found a statistically significant improvement in postural control on the frontal plane (Puls \& Gribble, 2007). In a study of the effects of 6-week combined agility and balance training on neuromuscular performance of basketball players, it was concluded that exercises which require balance improved neuromuscular performance (Zemková \& Hamar, 2010). Ameer et al. (2017) studied the relationship between the height of handball players and kyphosis and lordosis angles, and found that kyphosis and lordosis angles were higher in taller athletes, and that handball training led to a sagittal asymmetry, especially in tall athletes and emphasized the importance of rehabilitative exercises that these athletes should perform. The study and control groups were compared to prevent lower extremity force asymmetry, which is thought to be a risk factor for injuries due to sports branch in young tennis players, a significant decrease in the lower extremity force asymmetry of the study group was found after the given rehabilitative exercises (Sannicandro, Cofano, Rosa, \& Piccinno, 2014). In a study observing the effects of balance training of footballers on proprioception and lower extremity injuries, significant differences were found in the comparison of pretest-posttest results of the study group after balance training, and significant differences were found between the control and study groups regarding injuries (Malliou, Gioftsidou, Pafis, Beneka, \& Godolias, 2004). Spinal angles, curvatures and body composition of 
female volleyball players were compared with sedentary people, and it was found that the scapula and the triangle of the waist region of the volleyball players are more asymmetric and the volleyball players are mostly kyphotic, their lumbar lordosis are flattened and heads are frontally tilted. It has been proposed that thoracic kyphosis and asymmetry caused by the use of one side of the body can be reduced by performing yoga exercises (Grabara \& Hadzik, 2009). Postural asymmetry is determined in elite female volleyball players and It has been pointed out that asymmetry related to specific exercises is related to inadequate and inappropriate rehabilitative exercise (Vařeková, Vařeka, Janura, Svoboda, \& Elfmark, 2011).

\section{Conclusion}

Basketball is an acyclic sports branch which requires the use of the dominant side. This causes asymmetrical posture, sliding and tilts in the athletes. The effectiveness of soccer training, which does not require the use of one side of the body dominantly, in correcting the postural abnormalities is shown.

\section{References}

Ameer, M. A., \& Aziem, A. A. (2007). Relationship between anthropometric measures and sagittal spinal curvatures in adult male handball players. Human Movement, 18(4), 41-48. https://doi.org/10.1515/humo-2017-0035

Anderson, D. L., \& Sidaway, B. (1994). Coordination changes associated with practice of a soccer kick. Research Quarterly for Exercise and Sport, 2(65), 93-99. https://doi.org/10.1080/02701367.1994.10607603

Barczyk-Pawelec, K., Bańkosz, Z., \& Derlich, M. (2012). Body postures and asymmetries in frontal and transverse planes in the trunk area in table tennis players. Biology of Sport, 29, 129-134. Retrieved from https://kipdf.com/body-postures-and-asymmetries-in-frontal-and-transverse-planes-in-the-trunk-area_5ac34ebc172 3dd635a4779cd.html

Boland, D. M., Neufeld, E. V., Ruddell, J., Dolezal B. A., \& Cooper, C. B. (2016). Inter- and intra-rater agreement of static posture analysis using a mobile application. Journal of Physical Therapy Science, 28(12), 3398-3402. https://doi.org/10.1589/jpts.28.3398

Boldori, L., Da Soldà, M., \& Marelli, A. (1999). Anomalies of the trunk. An analysis of their prevalence in young athletes. Minerva Pediatrica, 51(7-8), 259-264. Retrieved from https://www.ncbi.nlm.nih.gov/pubmed/10634058?dopt=Abstract

Cosma, G., Ilinca, I., Rusu, L., Nanu, C., \& Burileanu, A. (2015). Physical exercise and its role in a correct postural alignment. Physical Education, Sport and Kinetotherapy Journal, 1(39), 58-64. Retrieved from https://www.researchgate.net/profile/Germina_Cosma/publication/279961540_PHYSICAL_EXERCISE_AND_IT S_ROLE_IN_A_CORECT_POSTURAL_ALIGNMENT/links/559fffad08ae967fb3e96a21/PHYSICAL-EXERCIS E-AND-ITS-ROLE-IN-A-CORECT-POSTURAL-ALIGNMENT.pdf

Downar, J. M., \& Sauers, E. L. (2005). Clinical measures of shoulder mobility in the professional baseball player. Journal of Athletic Training, 40(1), 23-29. Retrieved from https://www.ncbi.nlm.nih.gov/pmc/articles/PMC1088341/pdf/i1062-6050-40-1-23.pdf

Edwards, J., \& Alcantara, J. (2014). Successful clinical outcomes confirmed via ultrasound in a patient with placenta previa and breech fetal presentation with chiropractic care. Journal of Pediatric, Maternal \& Family Health, 13, 3-9. Retrieved from http://www.mccoypress.net/jpmfh/docs/2014-1295_placentaprevia.pdf

Fernández-de-Las-Peñas, C., Cuadrado, M. L., \& Pareja, J. A. (2006). Myofascial trigger points, neck mobility and forward head posture in unilateral migraine. Cephalalgia, 26(9), 1061-1070. Retrieved from http://journals.sagepub.com/doi/10.1111/j.1468-2982.2006.01162.x

Ferreira, E. A. G., Duarte, M., Maldonado, E. P., Burke, T. N., \& Marques, A. P. (2010). Postural assessment software (PAS/SAPO): validation and reliabiliy. Clinics, 65(7), 675-681. https://doi.org/10.1590/S1807-59322010000700005

Grabara, M. (2012). Analysis of body posture between young football players and their untrained peers. Human Movement, 13(2), 120-126. https://doi.org/10.2478/v10038-012-0012-7

Grabara, M. (2014). Anteroposterior curvatures of the spine in adolescent athletes. Journal of Back and Musculoskeletal Rehabilitation, 27(4), 513-519. https://doi.org/10.3233/BMR-140475

Grabara, M., \& Hadzik, A. (2009). Postural variables in girls practicing volleyball. Biomedical Human Kinetics, 1(1), 67-71. https://doi.org/10.2478/v10101-009-0017-7

Guedes, P. F., \& João, S. M. A. (2014). Postural characterization of adolescent federation basketball players. Journal of Physical Activity and Health, 11(7), 1401-1407. https://doi.org/10.1123/jpah.2012-0489 
Jandrić, S. Đ. (2016). Differences in postural disturbances between female adolescents handball players and nontraining peers. Vojnosanitetski Pregled. 73(4), 337-342. Retrieved from http://www.doiserbia.nb.rs/img/doi/0042-8450/2016/0042-84501600020J.pdf

Kayacan, Y., Çiftçioğlu, E., \& Soslu, R. (2014). The effect of basketball sport on some postural parameters. International Journal of Academic Research, 6(3), 23-27. https://doi.org/10.7813/2075-4124.2014/6-3/A.4

Kendall, F. P., McCreary, E. K., \& Provance, P. G. (2005). Muscles testing and function with posture and pain. 4th ed. USA: Lippincott Williams and Wilkins.

Knudson, D. (2007). Fundamentals of Biomechanics. (2nd. ed.) New York: Springer Science.

Leroy, D., Polin, D., Tourny-Chollet, C., \& Weber, J. (2000). Spatial and temporal gait variable differences between basketball, swimming and soccer players. International Journal of Sports Medicine, 21(3), 158-162. https://doi.org/10.1055/s-2000-9467

Lichota, M., Plandowska, M., \& Mil, P. (2011). The shape of anterior-posterior curvatures of the spine in athletes practising selected sports. Polish Journal of Sport and Tourism, 18, 112-121. http://suomentaekwondoliitto-fi-bin.directo.fi/@Bin/9f0f2563a019ae56ebf6f298531d3e97/1530871209/application /pdf/658001/Ryhtivirheet.pdf

Lohman, T. G., Roche, A. F., \& Martorell, R. M. (1988). Antropometric standardization reference manual. ABD: Champaign, Human Kinetics Books.

Malliou, P., Gioftsidou, A., Pafis, G., Beneka, A., \& Godolias, G. (2004). Proprioceptive training (balance exercises) reduces lower extremity injuries in young soccer players. Journal of Back and Musculoskeletal Rehabilitation. 17, 101-104. https://doi.org/10.3233/BMR-2004-173-403

Nichele da Rosa, B., Noll, M., Sedrez, J. A., Furlanetto, T. S., \& Candotti, C. T. (2016) Monitoring the prevalence of postural changes in schoolchildren. Journal of Physical Therapy Science, 28(2), 326-331. https://doi.org/10.1589/jpts.28.326

Pano, G., Çina, R., Murataj, G., Krist, A., Rusi, D. (2015). Postural and balance evaluation in 18-30 years old albaniana $\beta$-thalassemia patients. Journal of Human Sport and Exercise, 11(1), 251-258. https://doi.org/10.14198/jhse.2016.11.Proc1.17

Poca, M. A., Sahuquillo, J., Topczewski, T., Lastra, R., Font, M. L., \& Corral, E. (2006). Posture-induced changes in intracranial pressure: a comparative study in patients with and without a cerebrospinal fluid block at the craniovertebral junction. Neurosurgery, 58(5), 899-906. https://doi.org/10.1227/01.NEU.0000209915.16235.6D

Puls, A., \& Gribble, P. A. (2007). Comparison of two thera-band training rehabilitation protocols on postural control. Journal of Sport Rehabilitation. 16, 75-84. Retrieved from https://pdfs.semanticscholar.org/3a15/2baaf3491cc75a0645d5a6097d7581e3cc37.pdf

Puzovic, V., Rotim, K., Jurisic, V., Samardzic, M., Zivkovic, B., Savic, A., \& Rasulic, L. (2015). The prevalence of spine deformities and flat feet among 10-12 year old children who train basketball--cross-sectional study. Collegium Antropologicum, 39(3), 625-629. Retrieved from https://pdfs.semanticscholar.org/0e91/05df205284ab43a1c25705cece845144a845.pdf

Ribeiro, A., \& Pascoal, A. G. (2013). Resting scapular posture in healthy overhead throwing athletes. Manual Therapy. 18(6), 547-550. https://doi.org/10.1016/j.math.2013.05.010

Sannicandro, I., Cofano, G., Rosa, R. A., \& Piccinno, A. (2014). Balance training exercises decrease lower-limb strength asymmetry in young tennis players. Journal of Sports Science and Medicine, 13(2), 397-402. Retrieved from https://www.ncbi.nlm.nih.gov/pmc/articles/PMC3990896/pdf/jssm-13-397.pdf

Schmidt, R. A., \& Wrisberg, C. A. (2008). Motor Learning and Performance. America: Human Kinetics.

Shumway-Cook, A., \& Horak, F. B. (1986). Assessing the influence of sensory interaction of balance. Suggestion from the field. Physical Therapy, 66(10), 1548-1550. Retrieved from http://m.biodex.com/sites/default/files/article-assessing-the-influence-of-sensory-interaction-on-balance-16245.pdf

Sławińska, T., Rożek, K., \& Ignasiak, Z. (2006). Body asymmetry within trunk at children of early sports specialization. Polish Journal of Sports Medicine, 22(2), 97-100. Retrieved from http://www.medycynasportowa.edu.pl/api/files/view/9824.pdf

Stolinski, L., Kozinoga, M., Czaprowski, D., Tyrakowski, M., Cerny, P., Suzuki, N., \& Kotwicki, T. (2017). Two-dimensional digital photography for child body posture evaluation: standardized technique, reliable 
parameters and normative data for age 7-10 years. Scoliosis and Spinal Disorders, 12(38), 2-24. https://doi.org/10.1186/s13013-017-0146-7

Sung, D. H., Yoon, S. D., \& Park, G. D. (2015). The effect of complex rehabilitation training for 12 weeks on trunk muscle function and spine deformation of patients with SCI. Journal of Physical Therapy Science, 27(3), 951-954. https://doi.org/10.1589/jpts.27.951

Szucs, K. A., \& Brown, E. V. D. (2018). Rater reliability and construct validity of a mobile application for posture analysis. Journal of Physical Therapy Science, 30(1), 31-36. https://doi.org/10.1589/jpts.30.31

Trew, M., \& Everett, T. (2010). Human Movement. (6 $6^{\text {th }}$ ed.) Churchill Livingstone An Introductory Text, New York.

Uetake, T., Ohtsuki, F., Tanaka, H., \& Shindo, M. (1998). The vertebral curvature of sportsmen. Journal of Sports Sciences, 16(7), 621-628. https://doi.org/10.1080/026404198366425

Vařeková, R., Vařeka, I., Janura, M., Svoboda, Z., \& Elfmark, M. (2011). Evaluation of postural asymmetry and gross joint mobility in elite female volleyball athletes. Journal of Human Kinetics, 29(1), 5-13. https://doi.org/10.2478/v10078-011-0034-9

Zemková, E., \& Hamar, D. (2010). The effect of 6-week combined agility-balance training on neuromuscular performance in basketball players. The Journal of Sports Medicine and Physical Fitness, 50(3), 262-267.Retrieved from https://www.ncbi.nlm.nih.gov/pubmed/20842085

\section{Copyrights}

Copyright for this article is retained by the author(s), with first publication rights granted to the journal.

This is an open-access article distributed under the terms and conditions of the Creative Commons Attribution license which permits unrestricted use, distribution, and reproduction in any medium, provided the original work is properly cited. 